\title{
From the Desk of Honorary Secretary
}

Dear Members,

You may be aware that the 35th Annual General Meeting of the Institute for the Year 2000-2001 has just been held, and the members present again reelected me as the Honorary Secretary of the Institute for another successive year 2001-2002.

Let me apologise to all of you for not conducting our Annual General Meeting in time, i.e. by 30th September, 2001. One of the reason for the delay being the differences of opinions between our fellow members.

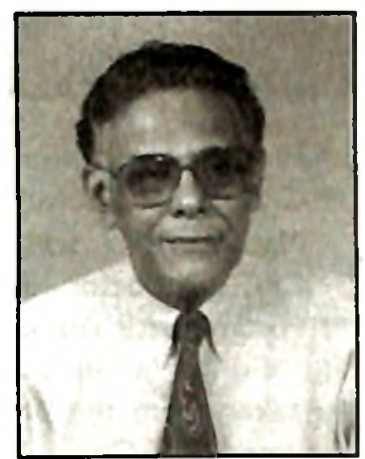

IWW is nearly 3100 members strong. Imagine how much stonger we would be if we can achieve our membership strength to a double. I would request to all IIW members to campaign for growth of IIW Membership so that we are betterly placed in membership strength. We must ensure that our membership is acceptable by the Industries at large.

You are also aware that in the era of Globalisation \& Liberalisation, our Industries have been facing tough competition. Let us help them by introducing Quality Management in Welding and also to utilise human resources by educating workers through ongoing tailor made training programme acceptable by the Industries.

AICTE (All India Council for Techincal Education) has accepted our AM-IIW Examination as equivalent to Degree status, through which our responsibilities have been increased substantially. Efforts are being made for opening Study Centres towards providing Quality Education \& Training for the prospective candidates.

Let us forget all our differences and work together for a united I.I.W. towards taking this Institute to a greater height.

Thanking you,

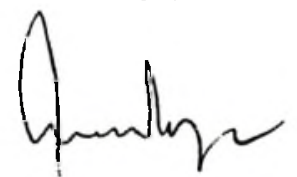

\section{A. !K. MUKHERJEE}

Honorary Secretary 